\title{
Overview of Carcinomas in Adolescents: A Descriptive Study Over Twenty Years
}

Brice Fresneau $^{1^{*}}$, Monique Fabre ${ }^{2}$, François Janot ${ }^{3}$, Martin Schlumberger ${ }^{4}$, Olivier Caron ${ }^{5}$, Nathalie Gaspar ${ }^{1}$, Dominique Valteau-Couanet ${ }^{1}$ and Laurence Brugières ${ }^{1}$

${ }^{1}$ Department of Pediatric oncology, Gustave Roussy, Université Paris-Saclay, Villejuif, F-94805, France

${ }^{2}$ Department of Pathology, Gustave Roussy, Université Paris-Saclay, Villejuif, F-94805, France

${ }^{3}$ Department of Head and Neck surgery, Gustave Roussy, Université Paris-Saclay, Villejuif, F-94805, France

${ }^{4}$ Department of Nuclear medicine and Endocrine oncology, Gustave Roussy, Université Paris-Saclay, Villejuif, F-94805, France

${ }^{5}$ Genetics unit, Gustave Roussy, Université Paris-Saclay, Villejuif, F-94805, France

\section{Abstract}

Purpose: In adolescents, carcinomas are rare tumors, accounting for $15 \%$ to $20 \%$ of cancers, with a wide spectrum.

Methods: Report of clinical, pathological and genetic characteristics of patients aged 12 to 18 years treated at Gustave Roussy for a carcinoma from 1990 to 2009.

Results: 204 adolescents, sex ratio F/M: 140/64, median age 16 years, were identified. Main sites were thyroid (40\%, with $67 / 82$ papillary carcinomas) and nasopharynx $(20 \%)$. Five-year OS and EFS of the whole cohort were respectively $75 \%(95 \% \mathrm{Cl} 0.68-0.80)$ and $64 \%(95 \% \mathrm{Cl} 0.57-0.71)$. We identified three risk groups: (1) thyroid and salivary gland carcinomas (5-y OS 100\%), (2) nasopharyngeal undifferentiated carcinomas and genital carcinomas (5-y OS 80\%), (3) others such as hepatocellular carcinomas, renal carcinomas and squamous cell carcinomas of the oral cavity (5-y OS 24\%). A genetic predisposition to cancer was identified in only 9/204 adolescents.

Conclusion: Thyroid and nasopharyngeal carcinomas are the most frequent sites and carry a good prognosis whereas squamous cell carcinomas of the oral cavity, hepatocellular carcinomas and non-localized renal carcinomas mostly portend a fatal outcome. International collaborative research between pediatric and medical oncologists is needed to improve the prognosis and to better understand the genetic determinants of these tumors with an unusual onset during adolescence.

Keywords: Carcinoma; Epidemiology; Descriptive study; Prognosis; Survival

\section{Introduction}

Whereas most tumors in adults are epithelial tumors, carcinomas are rare in patients under 20 years of age, and account for $9 \%$ of all childhood cancers between 10 and 14 years and $20 \%$ in patients aged 15-19 years [1,2]. In the SEER (National Cancer Institute's Surveillance, Epidemiology and End Results) registry, the carcinoma incidence rate in 2008-2012 was 12 between 10 and 14 years, and 44.6 between 15 and 19 years, per million (age-adjusted to the 2000 US standard population) [1].

In children and adolescents, the spectrum of carcinoma sites is different from those in adults in whom breast, colon, prostate and lung cancer account for more than $55 \%$ of all cases. Data in children and adolescents are based on registry analyses using the International Classification of Childhood Cancers (ICCC) [3] which identifies 3 main groups of carcinomas: kidney, liver and gonads carcinomas, and one supplementary group for other locations. In this last group, carcinomas are classified into five categories: adrenocortical, thyroid, nasopharyngeal and skin carcinomas, and others including colorectal, salivary, and lung carcinomas [2-6]. Thyroid carcinomas are the most frequent, with an incidence rate of 7.1 and 26.7 per million in patients aged 10-14 and 15-19, respectively. Other locations are much rarer with incidence rates of 1.7, 1.5, 1.3 and 1.1 per million in patients aged 15-19 for hepatic, nasopharyngeal, gonadal and renal carcinomas, respectively.

But in adolescents, these carcinomas may have different characteristics and prognosis from those in adults, leading to different treatment modalities according to age of diagnosis. In order to study in this population the characteristics of carcinomas, especially initial stage, therapeutic modalities and evolution, and to explore their differences with adults, we reported in this original study all cases of carcinomas in teenagers treated at Gustave Roussy during the last 20 years.

\section{Patients and Method}

All adolescents (age at diagnosis: 12 to 18 years) who had been treated for a carcinoma at Gustave Roussy between January 1, 1990, and December 31, 2009, were included in this study.

Carcinomas were defined as neoplasms derived from epithelial cells with cytokeratin expression by immunohistochemistry (IHC). Choroid plexus carcinomas, choriocarcinomas and embryonal carcinomas were excluded, and are analyzed with brain tumors and germ cell tumors. Melanomas which are not epithelial tumors, even though they are classified in ICCC group XI, were not included.

Pathological reports and clinical data recorded in medical files (gender, date of birth, date of diagnosis, site of the primary tumor,

*Corresponding author: Brice Fresneau, Department of Pediatric oncology, Gustave Roussy, 114 rue Edouard Vaillant, 94805 Villejuif, France, Tel: +330142114622; Fax: +33-0142115328; E-mail: brice.fresneau@gustaveroussy.fr

Received September 17, 2015; Accepted October 20, 2015; Published October 27, 2015

Citation: Fresneau B, Fabre M, Janot F, Schlumberger M, Caron O, et al. (2015) Overview of Carcinomas in Adolescents: A Descriptive Study Over Twenty Years. Arch Surg Oncol 1: 101. doi: 10.4172/2471-2671.1000101

Copyright: (c) 2015 Fresneau B, et al. This is an open-access article distributed under the terms of the Creative Commons Attribution License, which permits unrestricted use, distribution, and reproduction in any medium, provided the original author and source are credited. 
lymph node involvement and location of metastases, therapeutic interventions, date and vital status at last contact) were reviewed. When the histological diagnosis of carcinoma (in case of poorly differentiated malignant tumors) was doubtful, available slides were reviewed and additional IHC was performed using an anti-Pan Cytokeratin (AE1/ $\mathrm{AE} 3$ ) antibody $(\mathrm{Ab})$ to search for epithelial differentiation, anti-INI1 $\mathrm{Ab}$ to rule out a malignant rhabdoid tumor, and a monoclonal NUT Ab to detect NUT midline carcinomas (NMC) [7].

Concerning survival analysis, the main endpoint was overall survival (OS), defined as the time from randomization to death from any cause. The secondary endpoint, event-free survival (EFS), was defined as the time from randomization to progression, recurrence or death from any cause, whichever occurred first. Patients who had no events were censored at the date of last follow-up. Survival curves of PFS and OS according to histological subtype were estimated using the Kaplan-Meier method and differences between groups were tested using the log-rank test.

Clinical, genetic data and counseling recorded in medical files were reviewed in order to unveil arguments in favor of a genetic predisposition. We suspected genetic cancer predisposition in cases with a familial history of cancer or a personal medical history (proband with multiple tumors, developmental abnormalities such as psychomotor retardation, growth retardation, malformation syndrome, $>3$ café-au-lait spots).

\section{Results}

Between January 1, 1990, and December 31, 2009, 204 adolescents, (sex ratio F/M: 140/64), aged 12 to 18 (median age 16 years), were treated for a carcinoma at Gustave Roussy. The number of cases increased with age (Figure 1).

\section{Clinical, pathological and outcome characteristics}

The main sites were the thyroid $(n=82)$ and head and neck $(n=58)$ which accounted for $69 \%$ of all carcinomas. Distribution of primary tumor sites and pathological characteristics of carcinomas are detailed in Table 1 (in 34 cases, additional IHC was performed after slides review because of doubtful diagnosis).

With a median follow-up of 5.7 years, 5 year OS and EFS of the whole series of patients were respectively $74.6 \%$ (95\% CI 0.68-0.80) and 64.4\% (95\% CI 0.57-0.71) (Figure 2). We identified three risk groups with different OS (Figure 3): thyroid and salivary gland carcinomas (91 patients, 5-y OS 100\%), nasopharyngeal (NPC) and genital carcinomas (62 patients, 5-y OS 79.1\%, 95\% CI 0.66-0.88), and other carcinomas, including liver, renal and squamous cell carcinomas (SCC) of the oral cavity (51 patients, 5 -y OS $24.3 \%$, 95\% CI 0.14-0.39).

\section{Thyroid carcinomas}

Eighty-two patients were treated for a papillary (69), follicular (8) and medullary (5) carcinoma. At initial diagnosis, lymph node metastases were present in 57 cases (52 papillary, 3 follicular and 2 medullary) with lung metastases in 6 patients. Risk factors were identified in 7 cases: previous total body irradiation in 3 patients treated for acute leukemia 6 to 9 years before the diagnosis of thyroid carcinoma and multiple endocrine neoplasia (MEN) type 2 with a RET mutation in 4 of the 5 patients with medullary carcinoma.

All 25 patients with no loco-regional or distant metastases were free of disease after surgery and (131) I therapy in $13 / 25$ cases with a median follow-up of 7 years (range 0-19). Fifty-seven patients with lymph node involvement associated or not with lung metastases were treated with

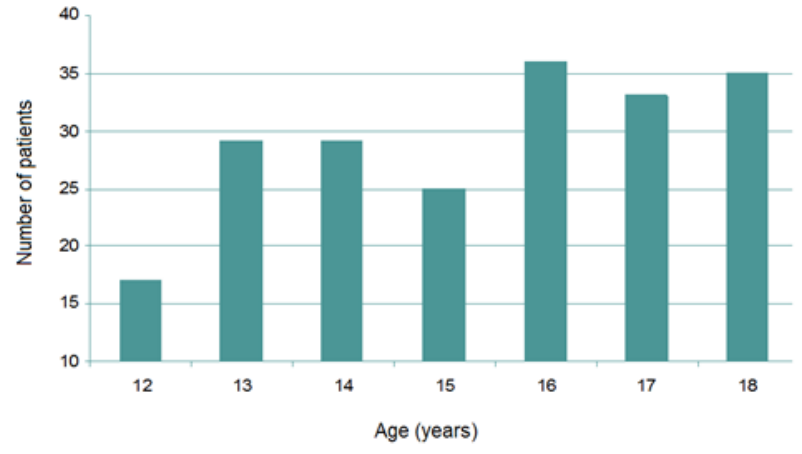

Figure 1: Age at diagnosis of 204 adolescents treated for a carcinoma.

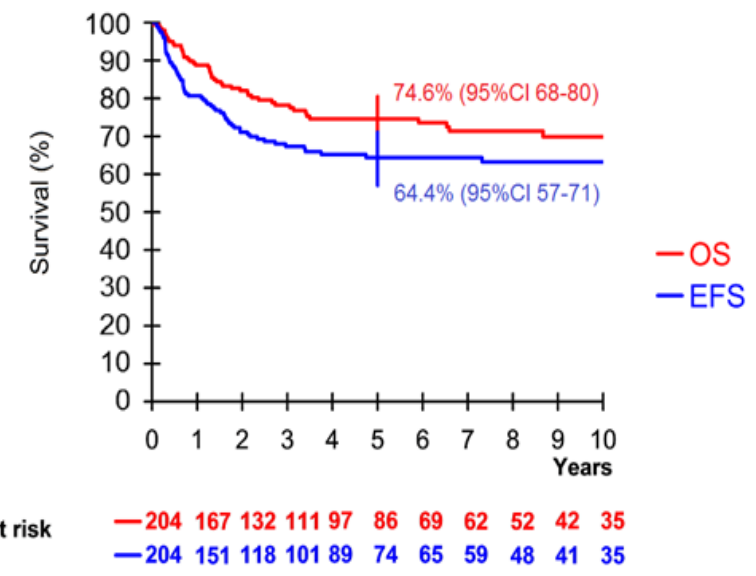

Figure 2: Kaplan-Meier estimates of overall survival (OS) and event free survival (EFS) of whole population.

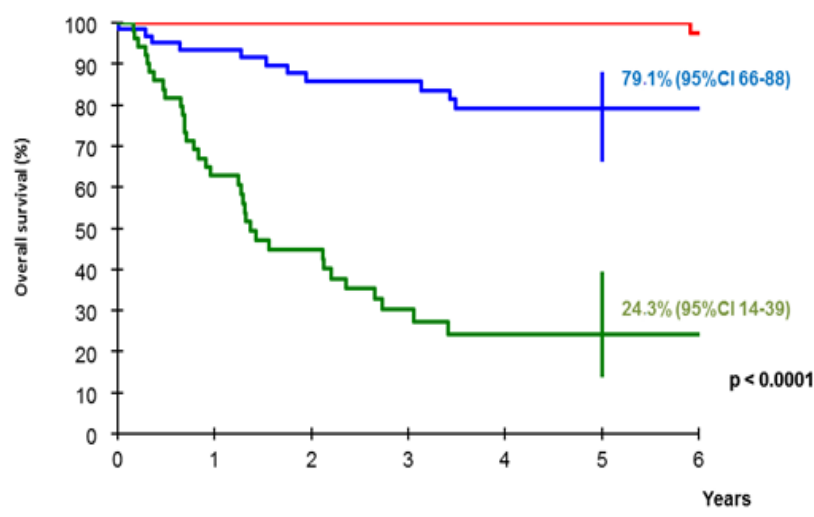

_ Thyroid and salivary glands _ _ NPC and genital _ _ Other

Figure 3: Kaplan-Meier estimates of overall survival (OS) of three risk groups: (i) thyroid and salivary glands, (ii) nasopharyngeal (NPC) and genital tract, (iii) other sites: oral and sinonasal cavity, liver, kidney, skin, digestive tract and other rare locations. $P$-value is for the log-rank test of comparison of the three risk groups. 
surgery (complete thyroidectomy) and (131) I therapy (except 5 cases). Among them, 15 (26\%) developed a local or metastatic recurrence after a median interval of 21 months (1 of them had no initial (131) I therapy), and 9 achieved a second complete remission. Five-year EFS was $88.3 \%$ (95\% CI $0.78-0.94)$. OS was $100 \%$ at $5 y$ and $97 \%$ at $10 y(95 \%$ CI 0.86-0.99). No patient died from progressive disease.

\section{Head and neck carcinomas}

Fifty-eight patients were treated for head and neck carcinomas: 40 NPC, 9 salivary gland carcinomas ( 7 in the parotid and 2 in accessory salivary glands) and 9 carcinomas of the oral and sinonasal cavity.

Nasopharyngeal carcinomas: Neck lymph node metastases were found at the initial diagnosis in 39/40 patients, with mediastinal lymph node extension in one case and bone metastases in other 4 cases. In situ hybridization detection of EBV-encoded RNA (EBER) was performed in 18 cases with positive results in $17 / 18$. All patients were treated with cisplatinum-based chemotherapy and radiotherapy. Among the 5 patients with initial distant metastases, only one was free of disease with a follow-up of 5 years. The 35 other patients achieved a first complete response but 7 relapsed ( 5 in lymph nodes, 2 in bones and 1 in lungs) among whom 5 died from their NPC. Five-year EFS and OS were respectively $69.8 \%$ (95\% CI $0.53-0.82 \%)$ and $76.7 \%$ (95\% CI $0.60-0.88 \%)$.

Salivary gland carcinomas: Two patients had lymph node involvement ( 1 acinar cell and 1 mucoepidermoid carcinomas). Treatment included surgery in all patients, combined with radiotherapy in $6 / 9$ cases (adenoid cystic carcinoma, lymph node involvement or incomplete surgery). After a median follow-up of 5 years (range 2-15), all patients were free of disease and no recurrence was observed.

Carcinomas of the oral and sinonasal cavity: Primary tumor site was the tongue in 7 cases of squamous cell carcinomas, tonsil and maxillary sinus in 2 cases of undifferentiated sinonasal carcinomas (negative for NUT immunohistochemistry). Lymph node involvement was found in 6 of them (all with primary tumor in the tongue). Two patients had inoperable tumor leading to palliative radiotherapy. All the 7 other patients underwent surgery (with partial glossectomy in $3 / 6$ tongue SCC), combined with radiotherapy in 2 cases or chemotherapy in 1 case. Six patients relapsed locally and died in the year after initial diagnosis. The only survivor was treated with preoperative chemotherapy (3 cycles of 5FU-Cisplatinum) with an impressive tumor response before radical surgery (follow-up: 10 years).

Female genital tract carcinomas: Twenty-two females were treated for a genital tract carcinoma, of the ovary in 16 and of the cervix or vagina in 6 .

Among the 16 patients with ovarian carcinomas, 5 patients ( 3 clear cell carcinomas, 1 serous carcinoma, 1 Krukenberg tumor) had initial peritoneal carcinomatosis with a fatal outcome in 3 cases despite radical surgery and adjuvant platinum-based chemotherapy. Only one of them was alive and free of disease 14 years later despite one cutaneous recurrence (oophorectomy's scar) treated with surgery, chemotherapy and high dose chemotherapy with autologous stem cell transplantation. Eleven patients had no initial peritoneal spread; all of them had an oophorectomy with, in 3 cases, adjuvant platinum-based chemotherapy (because of lymph node spread or incomplete surgery). One patient died after a peritoneal recurrence of a borderline serous carcinoma whereas the 10 other patients were free of disease.

Among the 6 patients with small cell carcinoma of the vagina or cervix, three patients had retroperitoneal lymph node involvement (associated with lung metastases in one case): one of them is alive but with progressive disease ( $4^{\text {th }}$ lymph node recurrence 4 years since initial diagnosis) and two died despite radiotherapy (with concomitant platinum-based chemotherapy and surgery in one case). The other 3 patients had no initial dissemination and were alive and free of disease, 7 to 20 years after surgery and brachytherapy. None of them was exposed to diethylstilbestrol during pregnancy.

Five-years EFS and OS of the whole group were respectively $55.5 \%$ (95\% CI 0.31-0.74) and 75.6\% (95\% CI 0.54-0.89).

\section{Liver carcinoma}

Seven fibrolamellar hepatocellular carcinomas (FL-HCC) and five common hepatocellular carcinomas (HCC) developed on normal liver (hepatitis B virus negative). Only $2 / 7$ patients with FL-HCC and $1 / 5$ HCC were alive with a follow-up of 47,77 and 74 months but after multiple recurrences treated with various combined therapies (multiple surgeries, chemotherapy, hyperthermic intraperitoneal chemotherapy, inhibitor tyrosine kinase, radiofrequency). The median survival of patients was 26 months (12-78) for FL-HCC and 16.5 months (8-25) for HCC.

\section{Renal carcinoma}

Eight patients were treated for a renal carcinoma, including 4 patients with juvenile clear cell carcinoma associated with the Xp11.2 translocation. Only $2 / 8$ patients (with juvenile clear cell carcinoma and Xp11.2 translocation) had localized disease treated by complete surgery only; they were alive and free of disease with a follow-up of 4 and 5 years. The other 6 patients had lymph node involvement with distant metastases in 4 , leading to progressive disease and death with a median survival of 11.5 months (range: 5-16) despite various combined therapies (surgery, chemotherapy, immunotherapy, radiotherapy).

\section{Other carcinomas}

Twenty-two patients were treated for carcinomas at other sites: 6 skin carcinomas, 4 digestive tract carcinomas including 1 colorectal carcinoma (hepatic and peritoneal metastases were present at diagnosis in 3/4 cases leading to a fatal outcome after a median survival of 9 months) and 12 other carcinomas (including 7 NUT negative undifferentiated carcinomas with a fatal course in the 6 patients with initial metastatic disease after a median survival of 8 months, and 3 metastatic adrenocortical carcinomas with a fatal outcome in all cases after a median survival of 9 months).

Staining for INI1 and NUT were performed respectively in 3 and 12 tumors, but no case of malignant rhabdoid tumor or NMC were diagnosed.

\section{Genetic characteristics}

Eighteen patients had a familial history of cancer and/or a personal medical history which led to suspect a genetic predisposition to cancer. A genetic predisposition had been identified in 6 of them (4MEN2, 1 MITF mutation, 1 Fanconi anemia). A description of these 18 patients is available in Table 2. Additionally, genetic counseling had been proposed to 26 other patients because of their young age. Among them, 3 patients had a genetic predisposition (1 TP53 mutation, 2 Gorlin syndromes, also described in Table 2).

\section{Discussion}

Adolescents carcinomas are a rare and heterogeneous tumor group, not previously described in a unique series. Between January 1990 and December 2009, 204 adolescents had been treated for a carcinoma at 


\begin{tabular}{|c|c|c|c|}
\hline & Males & Females & Total (\%) \\
\hline \multicolumn{4}{|l|}{ Thyroid } \\
\hline - Papillary & 13 & 54 & $67(32.1)$ \\
\hline - Follicular & 2 & 8 & $10(4.8)$ \\
\hline - Medullary & 2 & 3 & $5(2.4)$ \\
\hline \multicolumn{4}{|l|}{ Head and neck } \\
\hline - Undifferentiated NPC & 22 & 18 & $40(19.1)$ \\
\hline - Squamous cell carcinoma & 6 & 3 & $9(4.3)$ \\
\hline - Mucoepidermoid carcinoma & 3 & 2 & $5(2.4)$ \\
\hline - Acinar cell carcinoma & & 2 & $2(0.96)$ \\
\hline - Adenoid cystic carcinoma & 2 & & $2(0.96)$ \\
\hline \multicolumn{4}{|l|}{ Genital tract } \\
\hline \multicolumn{4}{|l|}{ - Cervix and vagina } \\
\hline - Small cell carcinoma & & 6 & $6(2.9)$ \\
\hline \multicolumn{4}{|l|}{ - Ovary } \\
\hline - Clear cell carcinoma & & 6 & $6(2.9)$ \\
\hline - Serous carcinoma & & 4 & $4(1.9)$ \\
\hline - Mucinous carcinoma & & 4 & $4(1.9)$ \\
\hline - Endometrioid carcinoma & & 1 & $1(0.48)$ \\
\hline - Krukenberg tumour & & 1 & $1(0.48)$ \\
\hline \multicolumn{4}{|l|}{ Liver } \\
\hline - FL-HCC & 3 & 4 & $7(3.3)$ \\
\hline - Common HCC & 1 & 4 & $5(2.4)$ \\
\hline \multicolumn{4}{|l|}{ Kidney } \\
\hline - Juvenile carcinoma & 2 & 4 & $6(2.9)$ \\
\hline $\begin{array}{l}\text { > with Xp11.2 } \\
\text { translocation }\end{array}$ & 2 & 3 & $5(2.4)$ \\
\hline - Papillary carcinoma & & 1 & $1(0.48)$ \\
\hline - Undifferentiated carcinoma & & 1 & $1(0.48)$ \\
\hline \multicolumn{4}{|l|}{ Skin } \\
\hline - Basal cell carcinoma & 1 & 3 & $4(1.9)$ \\
\hline - Squamous cell carcinoma & 1 & & $1(0.48)$ \\
\hline - Hidradenocarcinoma & 1 & & $1(0.48)$ \\
\hline \multicolumn{4}{|l|}{ Digestive tract } \\
\hline $\begin{array}{l}\text { - Adenocarcinoma (pancreas, } \\
\text { colon) }\end{array}$ & 2 & & $2(0.96)$ \\
\hline $\begin{array}{l}\text { - Squamous cell carcinoma } \\
\text { (esophagus) }\end{array}$ & 1 & & $1(0.48)$ \\
\hline - Undifferentiated (cardia) & 1 & & $1(0.48)$ \\
\hline Adrenal cell carcinoma & 1 & 2 & $3(1.4)$ \\
\hline $\begin{array}{l}\text { Soft tissue undifferentiated } \\
\text { carcinoma }\end{array}$ & & 3 & $3(1.4)$ \\
\hline Lung undifferentiated carcinoma & 1 & 1 & $2(0.96)$ \\
\hline Peritoneal adenocarcinoma & & 1 & $1(0.48)$ \\
\hline Breast : secretory carcinoma & & 1 & $1(0.48)$ \\
\hline $\begin{array}{l}\text { Undifferentiated carcinoma of } \\
\text { unknown primary }\end{array}$ & & 2 & $2(0.96)$ \\
\hline Total & 65 & 139 & $204(100)$ \\
\hline
\end{tabular}

NPC: Nasopharyngeal Carcinoma; FL-HCC: Fibrolamellar Hepatocellular Carcinoma; HCC: Hepatocellular Carcinoma

Table 1: Pathological characteristics of adolescent carcinomas.

Gustave Roussy, a comprehensive cancer center for childhood and adult malignancies.

Main sites were thyroid, head and neck and female genital tract. This site distribution presents few differences compared to the US SEER registry data [8] as well as to the French epidemiology report [9], with over-representation of nasopharyngeal carcinomas (NPC) and gynecologic tumors compared to thyroid carcinomas. In SEER registry, thyroid carcinoma incidence rate is 15 fold higher than NPC and gonadal carcinomas [1], whereas in our series, 82 thyroid carcinomas, $40 \mathrm{NPC}$ and 22 genital tract carcinomas were reported.
This might be due to different ethnic group repartition, population structure, sex ratio rate and environmental exposures. For example, nasopharyngeal carcinomas (NPC) rate which varies greatly according to ethnic origin $[10,11]$, was much higher in our series, probably due to different population representativeness. Over-representation of NPC as well as gynecologic tumors might also be explained by the renowned expertise of the Head and Neck and Gynecologic Surgery Departments at our institution. Over-representation of these two carcinoma types might participate to the relative under-representation of thyroid carcinomas. Further, since the discovery of germinal RET mutations in 1993; screening and treatment (total thyroidectomy) of gene carriers in NEM2A families are performed earlier during childhood that reduces medullary thyroid carcinoma incidence in adolescence.

Main types of carcinomas had good prognosis, with 100\% 5-y OS for thyroid and salivary gland carcinomas and 79.1\% 5-y OS for NPC and female genital tract carcinomas. These outcomes were similar than previously reported in literature.

Five-years EFS and OS rates of thyroid carcinomas were $88.3 \%$ and $100 \%$ respectively, comparable to that reported by the SEER registry (98\% 5-y OS and 91\% 30-y OS) [12]. Histology distribution and distant metastasis rate were also similar, but lymph node involvement was more frequent in our series ( $68 \%$ vs. $46.4 \%$ ) which may be related to lymph node dissection routinely performed in our institution. Even if the number of cases with distant metastases (6/82) was much too low to drive any conclusion, they are predictive of a worst outcome with a significant higher risk of cancer related death that may occur several decades after the initial diagnosis [13].

Concerning NPC, survival was quite similar to those previously reported (76.5\% 5y-OS vs. 71-81\%) [14-17]. The main indicator for poor prognosis was distant metastases which were present in only $12 \%$ of cases as compared to $2.7 \%$ to $27 \%$ in previous series. It is noteworthy that, compared with adults [18], adolescents NPC have more advanced stages ( $92 \%$ vs. $67 \%$ Stage III-IV) but significantly better overall survival (71\% vs. $58 \% 5 \mathrm{y}-\mathrm{OS})$.

Nevertheless, with 5-y EFS of 64.4\%, the overall outcome of adolescent carcinomas was worst in our series than in previous published data of registries ( $~ 80 \%$ in SEER registry), which might be due to recruitment bias and over-representation of poor prognosis carcinomas. Indeed, adolescents with hepatic, renal and squamous cell carcinomas (SCC) of the oral cavity had 5-y OS of $24.3 \%$. For example, in our series, 12 patients were treated for liver carcinomas with very poor prognosis (20\% 3y-OS) whereas in SIOPEL trials $3 \mathrm{y}$-OS was $42 \%$ for FL-HCC and $33 \%$ for HCC [19]. In the same way, only $2 / 8$ patients with renal cell carcinomas were alive and free of disease: only these two patients had localized disease and consequently could benefit of radical nephrectomy with clear margins [20,21]. In hepatic as well as in renal carcinomas, surgery is the cornerstone treatment. And only patients with localized disease and sufficient local control have been cured.

Local control is also of great importance in carcinomas of oral and sinonasal cavities, in which the main indicator for poor prognostic was advanced stage disease at diagnosis. Indeed, only patients with localized, completely resectable tumors have been successfully treated: 1/9 SCC of oral cavity. However, in previous studies, survival rates of oral cavity SCC were higher: $70 \% 5 y$-OS in the Memorial SloanKettering Cancer Centre series ( 10 tongues SCC, $3 / 10$ with lymph node involvement) [22] and 75.3\% 5y-OS in the SEER series (54 oral cavities SCC, $40 \%$ with lymph node spread) [23]. Lower OS may be explained in our series by more frequent lymph node involvement at diagnosis and the absence of radical surgery in most patients. SCC of oral cavity 
Citation: Fresneau B, Fabre M, Janot F, Schlumberger M, Caron O, et al. (2015) Overview of Carcinomas in Adolescents: A Descriptive Study Over Twenty Years. Arch Surg Oncol 1: 101. doi: 10.4172/2471-2671.1000101

Page 5 of 6

\begin{tabular}{|c|c|c|c|c|c|c|c|c|c|c|}
\hline \multirow[t]{2}{*}{$\mathbf{N}^{\circ}$} & \multicolumn{2}{|c|}{ Diagnosis } & \multicolumn{5}{|c|}{ Personal medical history } & \multicolumn{2}{|c|}{ Familial medical history } & \multirow{2}{*}{$\begin{array}{c}\text { Genetic } \\
\text { predisposisition }\end{array}$} \\
\hline & Carcinoma & $\begin{array}{c}\text { Age } \\
\text { (years) }\end{array}$ & Other tumors & Malformations & $\begin{array}{l}\text { Growth } \\
\text { retardation }\end{array}$ & $\begin{array}{l}\text { Psychomotor } \\
\text { retardation }\end{array}$ & Other pathologies & $\begin{array}{l}\text { First degree } \\
\text { relatives }\end{array}$ & $\begin{array}{l}\text { Second degree } \\
\text { relatives }\end{array}$ & \\
\hline 1 & $\begin{array}{l}\text { Adrenal cell } \\
\text { carcinoma }\end{array}$ & 15 & & & & & & & & TP53 \\
\hline 2 & SCC of tongue & 13 & & $\begin{array}{c}\text { facial } \\
\text { dysmorphy }\end{array}$ & + & + & $\begin{array}{l}\text { Angelman } \\
\text { syndrome }\end{array}$ & & & \\
\hline 3 & SCC of tongue & 18 & & & & & $\begin{array}{l}\text { Fanconi anemia, } \\
\text { allogenic SCT 7y } \\
\text { before }\end{array}$ & & & Fanconi anemia \\
\hline 4 & MEC & 15 & $\begin{array}{l}\text { Hodgkin lymphoma, } \\
\text { autologous SCT 8y } \\
\text { before }\end{array}$ & & & & & & $\begin{array}{l}\text { Testicular GCT } \\
\text { in paternal } \\
\text { grand father } \\
(28 \mathrm{y})\end{array}$ & \\
\hline 5 & NPC & 13 & & & & & $\begin{array}{l}\text { Multpile } \\
\text { hypopigmented } \\
\text { lesions }\end{array}$ & & & \\
\hline 6 & NPC & 15 & & & & & Sickle cell trait & & & \\
\hline 7 & NPC & 16 & $\begin{array}{l}\text { Triple negative breast } \\
\text { cancer 20y later }\end{array}$ & & & & $\begin{array}{c}\text { Multpile } \\
\text { melanocytic nevi }\end{array}$ & & & \\
\hline 8 & $\begin{array}{c}\text { Renal } \\
\text { undifferentiated } \\
\text { carcinoma }\end{array}$ & 13 & & & & & & & $\begin{array}{c}\text { Breast cancer } \\
\text { in maternal } \\
\text { grand mother } \\
(48 \mathrm{y})\end{array}$ & \\
\hline 9 & RCC Xp11.2 & 16 & & & & & & $\begin{array}{c}\text { Breast cancer } \\
\text { and melanoma } \\
\text { in mother }(50 \mathrm{y} \\
-58 \mathrm{y})\end{array}$ & & MITF \\
\hline 10 & RCC Xp11.2 & 17 & $\begin{array}{c}\text { Rhabdomyosarcoma } \\
\text { of bladder/prostate } \\
15 \mathrm{y} \text { before }\end{array}$ & & & & & $\begin{array}{l}\text { Breast cancer } \\
\text { in mother }(50 \mathrm{y})\end{array}$ & & \\
\hline 11 & FL-HCC & 14 & & & + & & & & & \\
\hline 12 & Common HCC & 16 & & & & & Delayed puberty & & & \\
\hline 13 & Follicular TC & 13 & $\begin{array}{c}\text { Acute leukemia, TBI } \\
\text { and allogenic SCT 6y } \\
\text { before }\end{array}$ & & & & & & & \\
\hline 14 & Follicular TC & 15 & $\begin{array}{c}\text { Acute leukemia, TBI } \\
\text { and allogenic SCT 9y } \\
\text { before }\end{array}$ & & & & & & & \\
\hline 15 & Papillary TC & 12 & $\begin{array}{c}\text { Acute leukemia, TBI } \\
\text { and allogenic SCT 6y } \\
\text { before }\end{array}$ & & & & & & & \\
\hline 16 & Medullary TC & 16 & Pheo. 10y later & & & & & & & MEN 2B \\
\hline 17 & Medullary TC & 17 & Synchronous Pheo. & & & & & & & MEN 2B \\
\hline 18 & Medullary TC & 14 & & & & & & $\begin{array}{l}\text { Medullary TC } \\
\text { in mother }\end{array}$ & & MEN 2A \\
\hline 19 & Medullary TC & 18 & & & & & & $\begin{array}{l}\text { Medullary TC } \\
\text { in mother }\end{array}$ & & MEN 2A \\
\hline 20 & $\begin{array}{l}\text { Basal cell } \\
\text { carcinoma }\end{array}$ & 13 & & & & & & & & Gorlin Syndrome \\
\hline 21 & $\begin{array}{l}\text { Basal cell } \\
\text { carcinoma }\end{array}$ & 18 & & & & & & & & Gorlin Syndrome \\
\hline
\end{tabular}

Table 2: Patients' description with suspected or detected genetic predisposition of cancer.

are rare in adolescents, but only convincing treatment according to guidelines in adults [22] could be efficient in such poor prognosis diseases. Adolescents with oral SCC have not better prognosis than adults, and consequently they need optimal treatment with complete surgery, even if sequelae are more important.

If surgery was very important in local control of adolescents' carcinomas, their poor prognosis was counter-balanced by the slow progression rate in few patients, leading to long survival, especially in hepatic carcinomas. Indeed 3 patients with liver carcinomas experienced long survival despite multiple recurrences with multimodal treatments, including surgery, chemotherapy, inhibitor tyrosine kinase and radiofrequency, showing the relevance of convincing surgery and additional therapy in liver carcinoma [24].

Treatment modalities should be discussed in multidisciplinary teams including adults' and pediatric oncologists and surgeons. Guidelines published for adults should be followed in these poor prognosis adult-type carcinomas, but because of different evolution and potential very long survivors, convinced treatment could be used in case of relapses.

If in predominant adult breast and colon carcinomas, early onset tumors are often associated with a genetic predisposition, in our series, only 9 patients had been diagnosed with cancer predisposing syndromes (4 MEN2, 2 Gorlin syndromes, 1 Fanconi anemia, 
Citation: Fresneau B, Fabre M, Janot F, Schlumberger M, Caron O, et al. (2015) Overview of Carcinomas in Adolescents: A Descriptive Study Over Twenty Years. Arch Surg Oncol 1: 101. doi: 10.4172/2471-2671.1000101

1 TP53 mutation, 1 MITF mutation) [25]. However, it is noteworthy that genetic counseling had been offered to only 44 patients. Given the rarity of these cancers in this age group, it is probably worth proposing genetic counseling to all adolescents with carcinomas in order to study the familial history of cancer, to look for associated abnormalities, to propose performing targeted tests based on clinical presentation and to bank DNA for future research when there is no obvious targeted test. Pediatric oncologists are not well aware of these targeted tests, consequently, genetic counseling seems to be necessary to determine which test is appropriate for which patient (PTEN and RET in thyroid cancer, VHL and MITF in renal carcinoma, PTCH in basal cell carcinoma, APC in polyposis, colon and liver carcinoma, MMR in colon carcinoma and other carcinomas of the Lynch syndrome of tumor spectrum...) [26-29]. Since TP53 mutations are associated with an excess risk of carcinomas, systematic screening of TP53 could be proposed but such systematic screening should probably be included in research protocols since childhood and adolescent carcinomas without familial history of cancer or multiple primary tumors are not included in the classic criteria for TP53 testing (except adrenocortical carcinoma or choroid plexus tumor, in which TP53 testing is always recommended irrespective of family history) [30].

In summary, adolescent carcinomas are rare tumors, which spectrum differs from their adult counterparts, and with a wide range of prognoses. Thyroid and nasopharyngeal carcinomas are the most frequent lesions carrying a good prognosis, while squamous cell carcinomas of the oral cavity, renal carcinomas and hepatocellular carcinomas have poorer prognosis. International collaborative research between pediatric and adult oncologists is needed to improve prognosis and to better understand genetic determinants of these tumors with an unusual onset during childhood or adolescence.

\section{Acknowledgments}

Special thanks for assistance to $S$. Piterboth, in performing immunohistochemistry, to G. Sebille, MD, in preparing the manuscript and helpful discussions, and to L. Saint Ange, in editing.

\section{References}

1. Howlader N, Noone AM, Krapcho M, Garshell J, Miller D, et al. (2015) SEER Cancer Statistics Review, 1975-2012. National Cancer Institute.

2. Desandes E, Clavel J, Berger C, Bernard JL, Blouin P, et al. (2004) Cancer incidence among children in France, 1990-1999. Pediatr Blood Cancer 43: 749757.

3. Steliarova-Foucher E, Stiller C, Lacour B, Kaatsch P (2005) International Classification of Childhood Cancer, third edition. Cancer 103: 1457-1467.

4. Cotterill SJ, Parker L, Malcolm AJ, Reid M, More L, et al. (2000) Incidence and survival for cancer in children and young adults in the North of England, 19681995: A report from the Northern Region Young Persons' Malignant Disease Registry. Br J Cancer 83: 397-403.

5. Reedijk AM, Janssen-Heijnen ML, Louwman MW, Snepvangers $Y$, Hofhuis WJ, et al. (2005) Increasing incidence and improved survival of cancer in children and young adults in Southern Netherlands, 1973-1999. Eur J Cancer 41: 760769 .

6. Birch JM, Alston RD, Kelsey AM, Quinn MJ, Babb P, et al. (2002) Classification and incidence of cancers in adolescents and young adults in England 19791997. Br J Cancer 87: 1267-1274.

7. Bauer DE, Mitchell CM, Strait KM, Lathan CS, Stelow EB, et al. (2012) Clinicopathologic features and long-term outcomes of NUT midline carcinoma. Clin Cancer Res 18: 5773-5779.

8. Wu XC, Chen VW, Steele B, Roffers S, Klotz JB, et al. (2003) Cancer incidence in adolescents and young adults in the United States, 1992-1997. J Adolesc Health 32: 405-415.
9. Desandes E, Lacour B, Belot A, Molinie F, Delafosse P, et al. (2013) Cancer incidence and survival in adolescents and young adults in France, 2000-2008. Pediatr Hematol Oncol 30: 291-306.

10. Burt RD, Vaughan TL, McKnight B (1992) Descriptive epidemiology and survival analysis of nasopharyngeal carcinoma in the United States. Int J Cancer 52: 549-556.

11. Cannon T, Zanation AM, Lai V, Weissler MC (2006) Nasopharyngeal carcinoma in young patients: A systematic review of racial demographics. Laryngoscope 116: $1021-1026$

12. Hogan AR, Zhuge Y, Perez EA, Koniaris LG, Lew Jl, et al. (2009) Pediatric thyroid carcinoma: Incidence and outcomes in 1753 patients. J Surg Res 156: 167-172.

13. Schlumberger M, De Vathaire F, Travagli JP, Vassal G, Lemerle J, et al. (1987) Differentiated thyroid carcinoma in childhood: Long term follow-up of 72 patients. J Clin Endocrinol Metab 65: 1088-1094.

14. Sultan I, Casanova M, Ferrari A, Rihani R, Rodriguez-Galindo C (2010) Differential features of nasopharyngeal carcinoma in children and adults: a SEER study. Pediatr Blood Cancer 55: 279-284.

15. Cheuk DK, Billups CA, Martin MG, Roland CR, Ribeiro RC, et al. (2011) Prognostic factors and long-term outcomes of childhood nasopharyngeal carcinoma. Cancer 117: 197-206.

16. Casanova M, Bisogno G, Gandola L, Cecchetto G, Di Cataldo A, et al. (2012) A prospective protocol for nasopharyngeal carcinoma in children and adolescents: The Italian Rare Tumors in Pediatric Age (TREP) project. Cancer 118: $2718-2725$.

17. Yan Z, Xia L, Huang Y, Chen P, Jiang L, et al. (2013) Nasopharyngeal carcinoma in children and adolescents in an endemic area: A report of 185 cases. Int J Pediatr Otorhinolaryngol 77: 1454-1460.

18. Downing NL, Wolden S, Wong P, Petrik DW, Hara W, et al. (2009) Comparison of treatment results between adult and juvenile nasopharyngeal carcinoma. Int J Radiat Oncol Biol Phys 75: 1064-1070.

19. Weeda VB, Murawski M, McCabe AJ, Maibach R, Brugières L, et al. (2013) Fibrolamellar variant of hepatocellular carcinoma does not have a better survival than conventional hepatocellular carcinoma--results and treatment recommendations from the Childhood Liver Tumor Strategy Group (SIOPEL) experience. Eur J Cancer 49: 2698-2704.

20. Indolfi $P$, Spreafico F, Collini P, Cecchetto G, Casale F, et al. (2012) Metastatic renal cell carcinoma in children and adolescents: A 30-year unsuccessful story. J Pediatr Hematol Oncol 34: e277-281.

21. Spreafico F, Collini P, Terenziani M, Marchianò A, Piva L (2010) Renal cell carcinoma in children and adolescents. Expert Rev Anticancer Ther 10: 19671978.

22. Morris LG, Patel SG, Shah JP, Ganly I (2010) Squamous cell carcinoma of the oral tongue in the pediatric age group: A matched-pair analysis of survival. Arch Otolaryngol Head Neck Surg 136: 697-701.

23. Morris LG, Ganly I (2010) Outcomes of oral cavity squamous cell carcinoma in pediatric patients. Oral Oncol 46: 292-296.

24. McAteer JP, Goldin AB, Healey PJ, Gow KW (2013) Surgical treatment of primary liver tumors in children: Outcomes analysis of resection and transplantation in the SEER database. Pediatr Transplant 17: 744-750.

25. Bertolotto C, Lesueur F, Giuliano S, Strub T, de Lichy M, et al. (2011) A SUMOylation-defective MITF germline mutation predisposes to melanoma and renal carcinoma. Nature 480: 94-98.

26. Weissman SM, Weiss SM, Newlin AC (2012) Genetic testing by cancer site: Ovary. Cancer J 18: 320-327.

27. Senter L (2012) Genetic testing by cancer site: Colon (nonpolyposis syndromes). Cancer J 18: 334-337.

28. Chan-Smutko G (2012) Genetic testing by cancer site: Urinary tract. Cancer J 18: 343-349.

29. Pilarski R, Nagy R (2012) Genetic testing by cancer site: Endocrine system. Cancer J 18: 364-371.

30. Tinat J, Bougeard G, Baert-Desurmont S, Vasseur S, Martin C, et al. (2009) 2009 version of the Chompret criteria for Li Fraumeni syndrome. J Clin Oncol 27: e108-109. 